\title{
Editorial: Temporal Patterns and Mechanisms of Biodiversity Across Scales in East Asia
}

\author{
Zehao Shen ${ }^{1 *}$, George P. Malanson ${ }^{2}$, Meng Yao ${ }^{1}$ and Jinlong Zhang ${ }^{3}$ \\ ${ }^{1}$ Ministry of Education Laboratory of Earth Surface Processes, College of Urban and Environmental Sciences, Institute of \\ Ecology, Peking University, Beijing, China, ${ }^{2}$ Department of Geography, lowa University, lowa City, IA, United States, ${ }^{3}$ Flora \\ Conservation Department, Kadoorie Farm and Botanic Garden, Hong Kong, China
}

Keywords: biodiversity, process, ecological, environmental, evolutionary, temporal scale

\section{Editorial on the Research Topic}

\section{Temporal Patterns and Mechanisms of Biodiversity Across Scales in East Asia}

OPEN ACCESS

Edited and reviewed by: Peter Convey, British Antarctic Survey (BAS), United Kingdom

*Correspondence: Zehao Shen

shzh@urban.pku.edu.cn

Specialty section:

This article was submitted to Biogeography and Macroecology,

a section of the journal

Frontiers in Ecology and Evolution

Received: 01 February 2021 Accepted: 18 February 2021 Published: 31 May 2021

Citation: Shen Z, Malanson GP, Yao M and Zhang J (2021) Editorial: Temporal

Patterns and Mechanisms of Biodiversity Across Scales in East Asia. Front. Ecol. Evol. 9:662454. doi: 10.3389/fevo.2021.662454
With regard to islands-the "type specimen" of biodiversity studies, the island biogeography model predicts species richness based on the spatial attributes, e.g., island area and distance to the mainland, but the theory is recognized as an equilibrium framework of dispersal, competition, and extinction processes (MacArthur and Wilson, 1967; Warren et al., 2015). In the past halfcentury, the geographical (especially latitudinal and altitudinal) distribution of species diversity and its explanations may be the most intensive area of biodiversity studies (Rohde, 1992; Rahbek, 1995; Willig et al., 2003; Pontarp et al., 2019). Spatially-based explanations, such as climatic gradients and habitat heterogeneity, and temporal hypotheses, for example environmental or speciation rate, are both supported. But the accumulating evidence increasingly demonstrated the importance of exploring temporal variations and process-based mechanisms at multiple scales for a final understanding of biodiversity variations on earth (Ricklefs, 1987). As an instant in hundreds of millions of years, the spatial pattern of biodiversity is just a snapshot of the evolutionary history of the biosphere. This perspective is embedded in either the "cradle—-museum-grave" framework of biodiversity at the macro-scale (Chown and Gaston, 2000; Jablonski et al., 2006; Qian et al., 2020), or the "niche-neutral-fitness" theory of community assembly and species coexistence at local scales (Leibold and McPeek, 2006; Adler et al., 2007).

Concurrently, rapid technological progress have enhanced our power and potential for exploring biogeographical evidence in deep time. On the one hand, the historical scenarios of environmental changes have been increasingly reconstructed for paleoclimate dynamics, plate tectonics and orogeny, wildfire regimes, and land-use and land-cover changes. On the other hand, the accumulation of dated fossil evidence and the establishment of molecular evolution models helped to disclose the evolutionary processes of speciation, migration, and extinction of various lineages of organisms. It is not surprising that the differences and combinations of spatiotemporal scales of various environmental changes, unique or similar evolutionary processes of different organism groups, convergence, or differentiation of various biotic functional traits, as well as interspecific and intraspecific interactions, have greatly enriched the character of biodiversity research in the past 50 years (Hembry and Weber, 2020).

Ultimately, the spatial pattern of biodiversity results from the overlay of distributions of taxa, and hence a hierarchical framework integrating processes across temporal, spatial, and trophic scales is critical for understanding biodiversity patterns. On the temporal aspect, a phylogenetic tree not only sets up a historical framework for the biogeography of a focal lineage, but also provides an approach to estimate the evolutionary relationship across taxa within a community, and help 
to reveal the effects of environmental filtering on the regional species pool (Wiens, 1998; Losos, 2008). On the spatial aspect, species niche modeling predicts species distribution ranges based on their local responses of presence/absence and population abundance to habitat conditions (Howard et al., 2014). Recently, prominent progress in the impact of cross-trophic biotic relationships on biodiversity have stimulated unprecedented attention (Chen L. et al., 2019; Wang et al., 2019). The interactions between microorganisms and higher plants and animals not only affect the species richness and composition at the community or site scale but also regulate the macroscale pattern of biodiversity (Ellis et al., 2015; Milici et al., 2020). The spread of the COVID-19 pandemic through human migration and its impact on human global behavior may be the latest footnote of the macro-micro interaction mechanism of biodiversity (Feng et al., 2020). Therefore, exploring the effects of eco-evolutionary process in response to environmental processes across scales seems to be one of the most important current tasks in understanding the spatiotemporal patterns of biodiversity.

Due to the individualistic response of species to environmental changes (Gleason, 1926; Whittaker, 1967), it will still be a long journey toward a deep understanding of the adaptive evolution of biological groups and the response of population dynamics (including growth, migration, and extinction) to multi-scale spatial-temporal changes of the environment. For this purpose, East Asia, traditionally composed of China, Japan, Korea, South Korea, and Mongolia, is undoubtedly one of the most valuable study areas in the world. The land in this area is composed of several blocks that were scattered in the southern and northern hemispheres in the Mesozoic, belonging to the Laurasia and Gondwana continents (Suo et al., 2020). In the Cenozoic, it experienced the uplift of the largest and highest plateau, the development of the strongest and largest monsoon in the world, and the largest land area in the northern hemisphere free from glaciers during the Quaternary ice ages (Batchelor et al., 2019). Since the Holocene, ecosystems in East Asia have probably experienced the most persistent and extensive human disturbance, including the largest scale deforestation, urbanization, and reforestation in China in the last 40 years (Cao et al., 2012; Chen C. et al., 2019; Wu et al., 2020). Therefore, the rich and unique biodiversity sources, the complexity of the evolutionary history of the biota, and the spatiotemporal heterogeneity of the environment provide incomparable opportunities to explore the temporal patterns and multi-scale mechanisms of biodiversity.

In this Research Topic, 11 research reports represent an effort with empirical approaches to understanding the temporal patterns and driving processes of biodiversity in East Asia, including the comparison of biodiversity at different times, the biogeographic evolutionary history of different biological assemblages, and the comparison and exploration of the effects of ecological and environmental processes on different temporal scales. The study area of these papers shares a common biogeographic context characterized by regional geological process (dominated by the uplift of Qinghai-Tibet Plateau), monsoon-regulated climates, and long histories of intensive human perturbation on natural ecosystems. Our Research Topic aims to reflect recent progress in studies at population, species, and community levels.

Three papers focused on ecological processes and their effects on biodiversity patterns at different spatial scales, Song et al. studied the effects of grazing exclusion on the composition, structure, and community spatial heterogeneity of the alpine grassland ecosystem on the Qinghai-Tibet Plateau; they found that the effects of grazing were differentiated by the duration of exclusion experiment (3-5 vs. 9-11 year). Zhang et al. addressed the effect of spatial heterogeneity or average supply rates of limiting resources. They reported that resource heterogeneity and local population dispersal, but not resource quantity, played an important role in determining species diversity in these two old-growth forests. In contrast, $\mathrm{Li}$ and Shen focused on the dispersal process of alien plants at a broad scale. By reconstructing the history of plant invasion in China and differentiating the geographical patterns of alien invasive plant species, the study found that low temperature and time since introduction were dominant determinants of invasive plant species diversity in China, which indicated that global warming and economic globalization would continue to driving forces of alien plant invasions.

Three papers explored the environmental processes that are particularly important for their influences on biodiversity patterns in China. Using phylogenetic tree construction and ancestral area reconstruction, Yan et al. focused on the role of the uplift of the Qinghai-Tibet Plateau in the phylogeography of a tree frog species Hyla chinensis. The paper delineated six clusters of the species and showed their spatial and temporal patterns. Dispersal models with different isolation estimates were compared to explain the spatial patterns of the present six groups within this complex. Xu et al. compared climate seasonality and glacial-interglacial climate variation for their roles on species richness patterns of evergreen broadleaved woody plants in China. They found that short- and long-term climate variability played complementary roles and should relate to distinct mechanisms. In particular, precipitation seasonality played a dominant role as a unique feature of the mid-latitude monsoon climate. Thus, a better understanding of the effects of climate change on species distributions requires exploration at multiple time scales. Urbanization is a spatial process that causes rapid landscape evolution as a product of economic globalization and has caused widespread concerns about regional scale biodiversity. Taking a space-for-time substitution approach, Yu et al. addressed the effect of urbanization on soil mesofauna diversity, and a median disturbance effect was reported for urbanization intensity as indicated by the interaction of landscape features and soil nutrients/heavy metal content.

The role of evolutionary process on contemporary biodiversity patterns was represented by two studies. Using a relaxed-clock method to estimate divergent times for Holcoglossum (Orchidaceae), Zhao et al. explored biogeographic patterns of this endemic epiphytic genus in East Asia. They inferred four dispersal events to explain the expansion of this genus to the Sino-Himalayan, Sino-Japanese, and Taiwan regions from the latest Miocene to Quaternary, and linked these events with the intensification of East Asian monsoon around 
3.6-2.6 Ma and global cooling since the latest Pliocene. Liu $\mathrm{X}$. et al. addressed the differentiation of Fagaceae in Hainan Island with fossil dating and distribution, and speculated on the dispersal and differentiation of genera of Fagaceae in tropical south China, including southern Yunnan, the Leizhou Peninsula of Guangdong, Hainan Island, and the southern part of Taiwan Island. The fossil evidence suggested the ancestral components of Fagaceae seemed to migrate southward from temperate regions of East Asia and diversified there no later than in the Eocene.

After decades of intensive exploration of patterns of biodiversity and underlying mechanisms, it is recognized that biodiversity has multi-facet and internally-linked information. This understanding is typically represented by measuring and comparing indices of taxonomic, phylogenetic, and functional diversity and relating them to environmental factors at multiple spatial and temporal scales (Liu L. et al.). Meanwhile, new diversity metrics also keep emerging to explore the temporal features of biodiversity. Li L. et al. explored the diversity of reproductive phenology among species of Poa and found the diversity of reproductive phenology among subtropical grasses is constrained by evolution and climatic niche, and that photosynthetic pathway and life history have an interactive effect on the timing and the duration of reproduction. Shi et al. compared phylogenetic and functional diversity and explored two aspects of diversity linked with mechanisms of biodiversity at distinct temporal scales: functional structure is better linked with modern and local factors while phylogenetic structure is more associated with historical and regional processes. These results highlighted the importance of the associations between the different biodiversity dimensions and divergent drivers.

With all efforts aiming to explain biodiversity patterns in terms of ecological, environmental, and evolutionary processes, evidence has been accumulating rapidly at various temporal scales and for distinct assemblages of organisms, including a small collection in this thematic issue. The importance of this approach is also indicated by the evolution of the interpretative framework in a process-based direction: from the "colonizationextinction" paradigm of island biogeography (MacArthur and

\section{REFERENCES}

Adler, P. B., HilleRisLambers, J., and Levine, J. M. (2007). A niche for neutrality. Ecol. Lett. 10, 95-104. doi: 10.1111/j.1461-0248.2006.00996.x

Batchelor, C. L., Margold, M., Krapp, M., Murton, D. K., Dalton, A. S., Gibbard, P. L., et al. (2019). The configuration of Northern Hemisphere ice sheets through the quaternary. Nat. Commun. 10:3713. doi: 10.1038/s41467-019-11601-2

Cao, G.-Y., Chen, G., Pang, L.-H., Zheng, X.-Y., and Nilsson, S. (2012). Urban growth in China: past, prospect, and its impacts. Popul. Environ. 33, 137-160. doi: 10.1007/s11111-011-0140-6

Chen, C., Park, T., Wang, X., Piao, S., Xu, B., Chaturvedi, R.K., et al. (2019). China and India lead in greening of the world through land-use management. Nat. Sustain. 2, 122-129. doi: 10.1038/s41893-019-0220-7

Chen, L., Swenson, N. G., Ji, N. N., Mi, X. C., Ren, H. B., Guo, L. D., et al. (2019). Differential soil fungus accumulation and density dependence of trees in a subtropical forest. Science 366, 124-128. doi: 10.1126/science.aau1361

Chown, S. L., and Gaston, K. J. (2000). Areas, cradles and museums: the latitudinal gradient in species richness. Trends Ecol. Evol. 15, 311-315. doi: 10.1016/S0169-5347(00)01910-8
Wilson, 1967) to the "cradle-museum" paradigm created by Chown and Gaston (2000), even to the random dispersal processbased neutral models of biodiversity (Hubbell, 2001; Colwell et al., 2004). In recent decades, genome technologies rapidly uncovered the genetic mechanisms of population dynamics and evolutionary process; remote sensing techniques improved the monitoring capacity for animal dispersal and landscape changes; isotopic techniques and fossil analyses helped with dating the geological processes of deep history. All these signs of technological progress combine to augment our capacity to explore the temporal aspect of biodiversity. The myriad patterns of biodiversity, with unique histories and geographies, manifest the complexity of mechanisms for its generation and maintenance. Disentangling the roles of multiple processes in determining biodiversity patterns seems to be a goal that still requires a long journey to achieve, while exploring biodiversity dynamics and driving processes at multiple temporal scales should prove to be a necessary and promising path.

\section{AUTHOR CONTRIBUTIONS}

ZS wrote the draft. GM, JZ, MY, and ZS revised the manuscript. All authors contributed to the article and approved the submitted version.

\section{FUNDING}

This work was sponsored by the Biodiversity Survey and Assessment Project of the Ministry of Ecology and Environment, China (Grant Number 2019-HJ-061-N-001-B-008).

\section{ACKNOWLEDGMENTS}

We appreciate the constructive review comments and suggestions from all reviewers, editors, and the guest editor team. We are grateful to the editorial office for their patience and great help with the review process. We thank all authors for their valuable contributions to this interesting Research Topic.

Colwell, R. K., Rahbek, C., and Gotelli, N. J. (2004). The mid-domain effect and species richness patterns: what have we learned so far? Am. Nat. 163, E1-E23. doi: $10.1086 / 382056$

Ellis, V. A., Collins, M. D., Medeiros, M. C. I., Sari, E. H. R. Coffey, E. D., Dickerson, R. C., et al. (2015). Local host specialization, host-switching, and dispersal shape the regional distributions of avian haemosporidian parasites. Proc. Natl. Acad. Sci. 112, 11294-11299. doi: 10.1073/pnas.1515309112

Feng, Y., Li, Q., Tong, X., Wang, R., Zhai, S., Gao, C., et al. (2020). Spatiotemporal spread pattern of the COVID-19 cases in China. PLoS ONE 15:e0244351. doi: 10.1371/journal.pone.0244351

Gleason, H. A. (1926). The individualistic concept of the plant association. Bull. Tor. Bot. Club 53, 7-26. doi: 10.2307/2479933

Hembry, D. H., and Weber, M. G. (2020). Ecological interactions and macroevolution: a new field with old roots. Annu. Rev. Ecol. Evol. Syst. 51, 215-243. doi: 10.1146/annurev-ecolsys-011720-121505

Howard, C., Stephens, P.A., Pearce-Higgins, J.W., Gregory, R.D., and Willis, S.G. (2014). Improving species distribution models: the value of data on abundance. Methods Ecol. Evol. 5, 506-513. doi: 10.1111/2041-210X. 12184 
Hubbell, S. P. (2001). The Unified Neutral Theory of Biodiversity and Biogeography. Princeton, NJ; Oxford: Princeton University Press.

Jablonski, D., Roy, K., and Valentine, J. W. (2006). Out of the tropics: evolutionary dynamics of the latitudinal diversity gradient. Science 314, 102-106. doi: 10.1126/science.113 0880

Leibold, M. A., and McPeek, M. A. (2006). Coexistence of the niche and neutral perspectives in community ecology. Ecology 87, 1399-1410. doi: 10.1890/0012-9658(2006)871399:COTNAN2.0.CO;2

Losos, J. B. (2008). Phylogenetic niche conservatism, phylogenetic signal and the relationship between phylogenetic relatedness and ecological similarity among species. Ecol. Lett. 11, 995-1007 doi: 10.1111/j.1461-0248.2008.01229.x

MacArthur, R. H., and Wilson, E. O. (1967). The Theory of Island Biogeography. Princeton, NJ: Princeton University Press.

Milici, V. R., Dalui, D., Mickley, J. G., and Bagchi, R. (2020). Responses of plantpathogen interactions to precipitation: implications for tropical tree richness in a changing world. J. Ecol. 108, 1800-1809. doi: 10.1111/1365-2745.13373

Pontarp, M., Bunnefeld, L., Cabral, J. S., Etienne, R. S., Fritz, S. A., Gillespie, R., et al. (2019). The latitudinal diversity gradient: novel understanding through mechanistic eco-evolutionary models. Trends Ecol. Evol. 34, 211-223. doi: 10.1016/j.tree.2018.11.009

Qian, H., Jin, Y., Leprieur, F., Wang, X., and Deng, T. (2020). Patterns of phylogenetic beta diversity measured at deep evolutionary histories across geographical and ecological spaces for angiosperms in China. J. Biogeogr. doi: $10.1111 /$ jbi.14036. [Epub ahead of print].

Rahbek, C. (1995). The elevational gradient of species richness: a uniform pattern? Ecography 18, 200-205. doi: 10.1111/j.1600-0587.1995.tb00341.x

Ricklefs, R. E. (1987). Community diversity: relative roles of and regional processes testing predictions of local-process theories. Science 235, 167-171 doi: $10.1126 /$ science. 235.4785 .167

Rohde, K. (1992). Latitudinal gradients in species diversity: the search for the primary cause. Oikos 65, 514-527. doi: 10.2307/3545569
Suo, Y., Li, S., Cao, X., Wang, X., Somerville, I., Wang, G., et al. (2020). MesozoicCenozoic basin inversion and geodynamics in East China: a review. Earth Sci. Rev. 210:103357. doi: 10.1016/j.earscirev.2020.103357

Wang, S., Brose, U., and Gravel, D. (2019). Intraguild predation enhances biodiversity and ecosystem functioning in complex food webs. Ecology 100:e02616. doi: 10.1002/ecy.2616

Warren, B. H., Simberloff, D., Ricklefs, R. E., Aguilée, R., Condamine, F. L., Gravel, D., et al. (2015). Islands as model systems in ecology and evolution: prospects fifty years after MacArthur-Wilson. Ecol. Lett. 18, 200-217. doi: $10.1111 /$ ele. 12398

Whittaker, H. (1967). Gradient analysis of vegetation. Biol. Rev.4, 207-264. doi: 10.1111/j.1469-185X.1967.tb01419.x

Wiens, J. J. (1998). Combining data sets with different phylogenetic histories. Syst. Biol. 47, 568-581. doi: 10.1080/106351598260581

Willig, M. R., Kaufman, D. M., and Stevens, R. D. (2003). Latitudinal gradients of biodiversity: pattern, process, scale, and synthesis. Annu. Rev. Ecol. Evol. Syst. 34, 273-309. doi: 10.1146/annurev.ecolsys.34.012103.144032

Wu, X., Wei, Y., Fu, B., Wang, S., Zhao, Y., and Moran, E. F. (2020). Evolution and effects ofthe social-ecological system over a millennium in China's Loess Plateau. Sci. Adv. 6:eabc0276. doi: 10.1126/sciadv.abc0276

Conflict of Interest: The authors declare that the research was conducted in the absence of any commercial or financial relationships that could be construed as a potential conflict of interest.

Copyright $\odot 2021$ Shen, Malanson, Yao and Zhang. This is an open-access article distributed under the terms of the Creative Commons Attribution License (CC BY). The use, distribution or reproduction in other forums is permitted, provided the original author(s) and the copyright owner(s) are credited and that the original publication in this journal is cited, in accordance with accepted academic practice. No use, distribution or reproduction is permitted which does not comply with these terms. 